\title{
Effect of predation risk and ectoparasitic louse flies on physiological stress condition of the red-tailed tropicbird (Phaethon rubricauda) from Rapa Nui and Salas \& Gómez islands
}

\author{
Nicolas Luna ${ }^{1,2}$, Andrea I Varela ${ }^{\text {Corresp., } 1}$, Guillermo Luna-Jorquera ${ }^{1,3}$, Katherina Brokordt ${ }^{3,4}$ \\ ${ }^{1}$ Millennium Nucleus for Ecology and Sustainable Management of Oceanic Islands (ESMOI), Departamento de Biologia Marina, Universidad Católica del \\ Norte, Coquimbo, Chile \\ 2 Programa de Magister en Ciencias del Mar Mención Recursos Costeros, Facultad de Ciencias del Mar, Universidad Católica del Norte, Coquimbo, Chile \\ 3 Centro de Estudios Avanzados en Zonas Áridas (CEAZA), Universidad Católica del Norte, Coquimbo, Chile \\ 4 Laboratorio de Fisiología y Genética Marina (FIGEMA), Departamento de Acuicultura, Universidad Católica del Norte, Coquimbo, Chile \\ Corresponding Author: Andrea I Varela \\ Email address: and.vrl@gmail.com
}

Background. Introduced predators at seabird colonies and parasites may have lethal and/or sub-lethal consequences for bird populations. We assessed the potential sub-lethal negative effects of these stressors in a native seabird listed as vulnerable in its south-eastern pacific distribution. This study was conducted in two red-tailed tropicbird (Phaethon rubricauda) colonies, one located in Rapa Nui Island, which is threatened by the presence of introduced predators, and the other located in Salas \& Gómez Island, which has no introduced predators, but birds are infested by ectoparasitic louse flies.

Methods. The effects on physiological stress traits of both, predation risk on different nest types (protected and exposed) on Rapa Nui, and different levels of louse flies' parasitic loads on Salas \& Gómez were studied. Three variables were analysed: the heterophil/lymphocyte $(\mathrm{H} / \mathrm{L})$ ratio, the transcriptional levels of mRNA HSP70 in blood, and the body condition. These stress indicators and leukocyte counts were compared between colonies.

Results. No significant differences were found in any stress indicator between different nest types within Rapa Nui, showing that the effect of predator's presence was the same for adults nesting in both, protected and exposed nests. No significant correlation was found between louse flies' parasitic loads and any stress indicators in the birds of Salas \& Gómez. Also, there was no difference in any stress indicator between islands. However, a significant opposite trend between islands was found in the eosinophil, lymphocyte, and monocyte counts when related to body condition.

Conclusions. We found a lack of significant differentiation in all the stress level indicators assessed within and between islands. The presence of louse flies in Salas \& Gómez v/s the absence of this parasite at Rapa Nui may be the cause for the significant difference in the trend of eosinophil, lymphocyte, and monocyte counts between the islands. However, further studies are necessary to elucidate the reason for this difference and to better investigate the lethal effects of introduced predators on the Rapa Nui colony to evaluate appropriate conservation measures for this native seabird. 
1 Effect of predation risk and ectoparasitic louse flies on physiological stress condition of the 2 red-tailed tropicbird (Phaethon rubricauda) from Rapa Nui and Salas \& Gómez islands 3

4 Nicolas Luna ${ }^{1,2}$, Andrea I Varela ${ }^{1}$, Guillermo Luna-Jorquera ${ }^{1,3}$ and Katherina Brokordt ${ }^{3,4}$ 5

$6{ }^{1}$ Millennium Nucleus for Ecology and Sustainable Management of Oceanic Islands (ESMOI),

7 Departamento de Biología Marina, Universidad Católica del Norte, Coquimbo, Chile; ${ }^{2}$ Programa

8 de Magister en Ciencias del Mar Mención Recursos Costeros, Facultad de Ciencias del Mar,

9 Universidad Católica del Norte; ${ }^{3}$ Centro de Estudios Avanzados en Zonas Áridas (CEAZA),

10 Coquimbo, Chile;

$11{ }^{4}$ Laboratorio de Fisiología y Genética Marina (FIGEMA), Departamento de Acuicultura,

12 Facultad de Ciencias del Mar, Universidad Católica del Norte, Coquimbo, Chile

13

14

15

16

17

18

19

20

21

22

23 Corresponding Author:

24 Andrea I Varela

25 Larrondo 1281, Coquimbo 1781421, Chile

26 Email: and.vrl@gmail.com

27

28 


\section{Abstract}

32 Background. Introduced predators at seabird colonies and parasites may have lethal and/or sublethal consequences for bird populations. We assessed the potential sub-lethal negative effects of these stressors in a native seabird listed as vulnerable in its south-eastern pacific distribution. This study was conducted in two red-tailed tropicbird (Phaethon rubricauda) colonies, one located in Rapa Nui Island, which is threatened by the presence of introduced predators, and the other located in Salas \& Gómez Island, which has no introduced predators, but birds are infested by ectoparasitic louse flies.

Methods. The effects on physiological stress traits of both, predation risk on different nest types (protected and exposed) on Rapa Nui, and different levels of louse flies' parasitic loads on Salas \& Gómez were studied. Three variables were analysed: the heterophil/lymphocyte $(\mathrm{H} / \mathrm{L})$ ratio, the transcriptional levels of mRNA HSP70 in blood, and the body condition. These stress

43 indicators and leukocyte counts were compared between colonies.

44 Results. No significant differences were found in any stress indicator between different nest types within Rapa Nui, showing that the effect of predator's presence was the same for adults nesting in both, protected and exposed nests. No significant correlation was found between louse

47 flies' parasitic loads and any stress indicators in the birds of Salas \& Gómez. Also, there was no 48 difference in any stress indicator between islands. However, a significant opposite trend between 49 islands was found in the eosinophil, lymphocyte, and monocyte counts when related to body 50 condition.

51 Conclusions. We found a lack of significant differentiation in all the stress level indicators

52 assessed within and between islands. The presence of louse flies in Salas \& Gómez v/s the 
53 absence of this parasite at Rapa Nui may be the cause for the significant difference in the trend of

54 eosinophil, lymphocyte, and monocyte counts between the islands. However, further studies are

55 necessary to elucidate the reason for this difference and to better investigate the lethal effects of

56 introduced predators on the Rapa Nui colony to evaluate appropriate conservation measures for

57 this native seabird. 


\section{Introduction}

60 Seabirds on most oceanic islands have evolved in the absence of terrestrial predators (Coulson

61 2002), and predation can be due to other seabirds (Baird 1996), and secondarily by raptors birds

62 like owls and hawks (Glue 1972; Hamer et al. 2002). There is good evidence that alien or

63 introduced terrestrial predators are a severe threat to a wide variety of seabird species (Coulson

64 2002; Caut et al. 2008; Jones et al. 2008). The most typical introduced predators are rats,

65 especially from the genus Rattus, feral cats and dogs, among others (Nogales et al. 2004; Krajick

66 2005; Caut et al. 2008; Jones et al. 2008; Croxall et al. 2012). Predators may affect seabird

67 populations by lethal interactions (e.g., predation) and/or non-lethal interactions as the result of

68 predation threat (Cresswell 2008). Non-lethal interactions can alter birds at the ecological level.

69 For example, foraging seabirds can avoid suitable feeding areas in response to predation risk

70 (reviewed by Cresswell 2008), but also may have other negative physiological consequences. For

71 example, predator vocalizations were interpreted as a danger cue by the Neotropical blue-black

72 grassquits (Volatinia jacarina), inducing dramatic changes in the proportion of heterophils and

73 lymphocytes, and generating immune depression (Caetano et al. 2014). Similarly, the presence of

74 predators increased stress protein expression in late breeding pied flycatchers (Ficedula

75 hypoleuca) (Thomson et al. 2010). These studies support the idea that predation risk may affect

76 the physiological condition of prey organisms at different levels. So far, to the best of our

77 knowledge, studies regarding the potential negative effects of predation risk on the physiological

78 condition of seabirds are lacking.

79 Like predation, parasitism has negative lethal and sub-lethal effects on birds (Boyd 1951).

80 Birds are exposed to a wide variety of ectoparasites, including biting lice (Mallophaga) fleas

81 (Siphonaptera), bugs and triatomines (Hemiptera), and flies (Diptera) (Boyd 1951). Parasites can 
82 decrease physiological status of their host birds by altering their immune system, changing, for

83 example, white blood cell proportions (Davis et al. 2008), and stress protein levels in blood

84 (Martinez-de la Puente et al. 2011). They may have further deleterious effects on their host's life

85 history traits, affecting growth (Fitze et al. 2004), breeding success (Møller 1993; Martinez-de la

86 Puente et al. 2011), and survival of birds (Boyd 1951), and can even drive hosts to local

87 extinction (Koop et al. 2016). In particular, flies from the family Hippoboscidae (order Diptera),

88 commonly called "louse flies", are obligate ectoparasitic blood feeders (Rahola et al. 2011) and

89 have been reported to parasitize at least 18 different orders of birds (Santos et al. 2014). Species

90 of the Hippoboscidae are also known to act as infectious vectors in transmitting haemosporidian

91 blood parasites to seabirds (Rahola et al. 2011), thus activating the host immune system (Padilla

92 et al. 2006; Levin et al. 2011). Further, high parasitic loads by louse flies have been shown to

93 decrease avian fitness by reducing the breeding success of adults and reducing the weight, size

94 and survivorship in nestlings (Loye \& Carroll 1995).

95 A widely used methodology to assess stress levels in birds, and many taxa among vertebrates,

96 is the examination of leukocyte profiles from blood smears (Davis et al. 2008). Some leukocytes

97 are altered by stress hormone levels, and thus are indirectly associated with stress status (Davis et

98 al. 2008). Among leukocyte proportions, the estimation of the ratio between circulating

99 heterophils and lymphocytes (H/L ratio) is commonly used as a stress indicator, because

100 heterophils (H) and lymphocytes (L) are altered by stress in opposite directions, and so the H/L

101 ratio varies with stress levels (Maxwell \& Robertson 1998; Quillfeldt et al. 2008; reviewed by

102 Davis et al. 2008). Further, the relative number of monocytes and eosinophils are also important

103 to discriminate whether $\mathrm{H} / \mathrm{L}$ ratios are high due to stress, disease or parasites. Monocytes due to

104 their potential phagocytic function increase their proportion due to infections or intracellular 
105 parasites such as viruses and certain bacteria, while eosinophils increase due to infections with

106 parasites such as worms and protozoa (Maxwell 1993; Davis et al. 2008).

107 Another indicator of physiological stress in birds is the expression levels of the heat shock

108 proteins (HSPs). Expression levels of HSPs are induced by different factors, like heat/cold shock,

109 physical activity, and toxins (Sørensen et al. 2003; Brun et al. 2008). Further, changes in these

110 proteins in the blood have been related to bird responses to stress caused by low food

111 availability, social interactions, predation risk, and parasites, among other factors (Tomás et al.

112 2004; Thomson et al. 2010; Martinez-de la Puente et al. 2011). A positive correlation between

113 HSP60 levels in blood and ectoparasite infestation was observed in a manipulative experiment

114 with nesting blue tits Cyanistes caeruleus (Martinez-de la Puente et al. 2011). Similarly, an

115 increase of HSP70 expression levels was found in nesting pied flycatchers (Ficedula hypoleuca)

116 due to increasing predation risk (Thomson et al. 2010).

117 Body condition is usually a reflection of the physiological status and is commonly used as a

118 proxy for an individual's energy stores (Jacobs et al. 2012). It can be estimated as a ratio

119 between observed body mass and an expected body mass calculated for each bird using

120 morphological measurements (Plischke et al. 2010). Researchers mostly relate condition index to

121 breeding success, bird survival, and behaviour (Brown 1996; Labocha \& Hayes 2012), and it is

122 generally accepted that a "good body condition" is synonymous of a "healthy animal".

123 Therefore, there are many attempts especially in physiological research to test the hypothesis that

124 adverse environmental conditions negatively affect the body condition (e.g., Thomson et al.

125 2010), as responding to these conditions involves energy-consuming processes (Suorsa et al.

126 2004; Cresswell 2008; Dehnhard et al. 2011; Labocha \& Hayes 2012).

127 A model species to assess the potential pervasive effects of predation risk and parasitism in 
128 seabirds that breed at oceanic islands is the red-tailed tropicbird, Phaethon rubricauda. This

129 tropicbird is one of the three species of the Family Phaethontidae (Order Phaethontiformes); it

130 occurs in tropical and sub-tropical areas of the Pacific and Indian Oceans and breeds on oceanic

131 islands and islets (del Hoyo et al. 1992). They are monogamous, ground-nesters, and both sexes

132 share reproductive duties evenly (Fleet 1974). In Chile, in the south-eastern Pacific Ocean, the

133 species breeds only in Rapa Nui (also known as Eastern Island), Salas \& Gomez and

134 Desventuradas Islands (Aguirre et al. 2009; Flores et al. 2014), where it has been categorized as

135 a vulnerable species (Ministry of the Environment, Chile, 2017).

136 The present study was conducted in two red-tailed tropicbird colonies, one located in Rapa

137 Nui and the other in Salas \& Gómez. Rapa Nui is an inhabited island located $\sim 3,700 \mathrm{~km}$ from

138 mainland Chile $\left(27^{\circ} 09^{\prime} \mathrm{S}, 109^{\circ} 26^{\prime} \mathrm{W}\right)$. The assessed colony is located at the Rano Raraku

139 volcano in the eastern part of the island. This colony is almost free of louse flies (personal

140 observation, 2016), but introduced predators are present, including rats of the genus Rattus, feral

141 cats, feral dogs, and the raptor bird chimango caracara (Phalcoboenus chimango) (Flores et al.

142 2017; Luna et al. 2018). Two distinctive red-tailed tropicbird nest types were recognized in this

143 colony, one covered by rocks (sometimes moais or inside caves) characterized as "protected",

144 and the other type covered only by grass, with little or no rocky protection, characterized as

145 "exposed" (as describe Prys-Jones and Peet 1980). Luna et al. (2018) registered the presence of

146 introduced rats in $75 \%$ of the assessed nests, while avian predators only visited an exposed nest,

147 suggesting that exposed nests might be more vulnerable, as they are also threatened by aerial

148 predators in addition to terrestrial predators.

149 In contrast, Salas \& Gomez Island is a small uninhabited island, located $390 \mathrm{~km}$ east of Rapa

150 Nui $\left(26^{\circ} 27^{\prime}\right.$ S, $\left.105^{\circ} 28^{\prime} \mathrm{W}\right)$ within the Motu Motiro Hiva Marine Park. Unlike the Rapa Nui 
151 colony, at this island red-tailed tropicbirds nest on the ground, mostly under rocky protection,

152 probably because of the lower presence of grass and vegetation (personal observation 2016).

153 This island has no native or introduced terrestrial predators, but louse flies have been found in

154 most assessed red-tailed tropicbird individuals, some of them with more than 20 flies (personal

155 observation 2016).

156 The aim of this study was to determine whether both the presence of introduced predators in

157 the Rapa Nui colony, and parasitism by louse flies in the birds of Salas \& Gómez affect the stress

158 levels of red-tailed tropicbirds. Three main variables were analysed to assess the physiological

159 stress: (a) the H/L ratio, (b) the transcriptional levels of HSP70 in blood, and (c) the body

160 condition. Furthermore, these stress indicator levels were compared between both colonies, in

161 order to evaluate which stressors (i.e. predation risk v/s parasitic infestation) had a higher effect

162 on the physiological and condition status of red-tailed tropicbird populations in the Rapa Nui

163 ecoregion. Results could contribute to better understand the sub-lethal effects of introduced

164 predators and parasites on native species.

165 Three main hypotheses were evaluated in this study: (1) Red-tailed tropicbirds of the Rapa

166 Nui colony nesting in nests with potentially higher predation risk (exposed) will show higher

167 levels of physiological stress and lower body condition than conspecifics nesting in nests with

168 lower predation risk (protected); (2) Red-tailed tropicbirds of the Salas \& Gómez colony with

169 higher louse flies' parasitic load will show higher levels of physiological stress and lower body

170 condition than conspecifics with lower parasitic load; (3) Red-tailed tropicbirds of the Salas \&

171 Gómez colony will show higher physiological stress and lower body condition due to chronic

172 parasitic infestation than the red-tailed tropicbirds of the Rapa Nui colony where the presence of

173 predators at nests is not permanent. 


\section{Materials \& Methods}

\section{Sample collection}

176 In both colonies, nests are scattered through the breeding area and just a few are next to each

177 other. A total of 51 red-tailed tropicbird adults were captured at their nests by hand and assessed

178 for blood analyses and body condition. Twenty-six birds were sampled on Rapa Nui and 25 on

179 Salas \& Gómez. In Rapa Nui, nine birds were assessed in August 2016, and 17 birds were

180 assessed in June 2017. Of these 26 birds, 20 were incubating one egg, one was rearing a recently

181 hatched chick and five had neither egg nor chick on their nests. On June 2017, nests were

182 categorized as "protected" (totally or partially covered by rocks or moais or inside crevices) and

183 as "exposed" (covered by grass only). On Salas \& Gómez nine birds were assessed in August

184 2016, nine in November 2016, and seven in June 2017. Of these 25 birds, 19 were incubating

185 one egg, two were rearing a chick and four had neither egg nor chick on their nests.

186 Data of all birds assessed in both islands were used to compare physiological stress indicators

187 and body condition between islands. Because only two birds from Rapa Nui captured in August

1882016 had louse flies (each having only one fly), the evaluation of physiological stress for this

189 colony only considered predation risk at different nest types as explanatory variable and not

190 parasitic load. Similarly, because of the absence of introduced terrestrial or avian predators on

191 Salas \& Gómez, the parasitic load alone was considered as the explanatory variable for this

192 colony.

193 Prior to blood sampling and body condition assessment, birds were examined for the presence

194 of louse fly parasites. Flies inhabit the bird and they move over and between the feathers,

195 therefore they can be captured by hand, searching them between the feathers. When flies flew

196 away, they quickly returned to the host, which facilitated their capture. All flies were removed 
197 manually within the first 5 minutes of handling and stored in a zip lock plastic bag with acetate

198 soaked cotton to kill them, and then preserved in $90 \%$ ethanol for later quantification and

199 identification. Parasitic load was considered as the absolute number of flies removed from each

200 bird within 5 minutes of examination, always by the same observer. Flies were identified

201 according to Bequaert (1941), Maa (1966), and Santos et al. (2014).

202

203 Blood sampling and body condition assessment

204 During manipulation, the head of the captured birds was covered with a cotton bag to reduce

205 their vision and therefore reduce manipulation stress. A $300 \mu \mathrm{L}$ blood sample was taken from the

206 right wing brachial vein with a hypodermic syringe. $200 \mu \mathrm{L}$ of blood was distributed evenly in

207 two cryogenic tubes containing $1 \mathrm{ml}$ of Trizol RNA preserving reagent (Ambion ${ }^{\circledR}$ ), and

208 homogenized for later determination of mRNA HSP70 relative transcriptional levels. Samples

209 were kept in a cool box with icepacks until being stored at $4{ }^{\circ} \mathrm{C}$ during the field trip and at $-80^{\circ} \mathrm{C}$

210 once at the laboratory. Additionally, a drop of blood was smeared on two glass slides and air-

211 dried for later leukocyte count analysis. Smears were fixed with absolute methanol and stained

212 with Giemsa for 30 min, following Dehnhard et al. (2011). After the blood sampling procedure,

213 morphological measurements were taken for each bird. Bill, skull and tarsus length were

214 measured using a calliper (accuracy of $0.05 \mathrm{~mm}$ ). Wing length was measured to the nearest $1 \mathrm{~cm}$

215 with a ruler, as the distance of the longest primary from the radio-carpal joint to the tip.

216 Morphological measurements data of all birds assessed can be found as supplemental material

217 (Table S1). Each bird was then introduced in a cotton fabric bag and weighed using a $1000 \mathrm{~g}(10 \mathrm{~g}$

218 accuracy) Pesola scale. The whole manipulation lasted 10 minutes maximum and birds were

219 always returned in good conditions to their nests. 
The manipulation of the birds, including blood extraction, was authorized by the Agricultural

221 and Livestock Service (SAG), Chile, trough the permits "Resolución exenta N9894/2015" and

222 "Resolución exenta N5343/2016". The Ethics committee of the Universidad Católica del Norte,

223 Coquimbo, Chile, granted Ethical approval to carry out this study (Resolución F.M. N¹2).

224 Access to the colony at the Rapa Nui National Park was authorized by the indigenous

225 community of Ma'u Henua and by the National Forest Corporation-Rapa Nui (CONAF-Rapa 226 Nui).

227

228 Leukocyte analysis and $\mathrm{H} / \mathrm{L}$ ratio

229 Blood smears were examined under a light microscope (100x, oil immersion) in a monolayer

230 sector of the smear. Two samples, one from Rapa Nui and one from Salas \& Gómez, were

231 excluded from leukocyte analysis as the smears were in deficient conditions.

232 Two smears were analysed for each bird. Following the method described by Davis (2005),

233 white blood cells were quantified and grouped into five different leukocyte types (heterophils,

234 lymphocytes, eosinophils, monocytes and basophils) until a minimum of 100 leukocytes per slide

235 had been registered. Total erythrocytes were calculated as a mean of all erythrocytes counted in 6

236 microscope visual fields multiplied by the number of visual fields that were scanned to obtain

237100 leukocytes. The estimation of the relative number of each leukocyte type was calculated as

238 the percentage of all leukocytes following the method proposed by Davis (2005). All five

239 leukocyte types were standardized to 10,000 erythrocytes: each leukocyte type was multiplied by

24010,000 and then divided by total erythrocytes. To calculate the $\mathrm{H} / \mathrm{L}$ ratio for each bird, the mean

241 of each standardized leukocyte of both smears was calculated, and then the H/L ratio was

242 determined as heterophils in 10,000 erythrocytes divided by lymphocytes in 10,000 erythrocytes. 


\section{HSP70 transcriptional level determinations}

245 Total RNA was extracted from each blood sample using the Trizol reagent (Ambion®) following

246 the manufacturer instructions. Total RNA was quantified with an Epoch spectrophotometer

247 (BioTek) using a plate for microvolumes Take3 ${ }^{\mathrm{TM}}$ (BioTek) and the purity was evaluated by the

248 A260/280 ratio (values between 1.8-2.0 indicate that the extracted RNA is free of DNA and

249 phenols). Intactness was verified by visual inspection of RNA bands in denaturing

250 formaldehyde/agarose gel electrophoresis stained with SYBR® Safe (Thermo Fisher Scientific).

251 Samples were considered intact if 28S and 18S rRNA bands were sharp and discrete with an

252 absence of smearing under each band, and fluorescence intensity of the 28S rRNA band

253 appeared to be twice as intense as the 18S rRNA band. After this inspection, of the total 51

254 samples, nine were discarded for HSP70 transcriptional level determination. Extracted RNA was 255 stored at $-80^{\circ} \mathrm{C}$ for further use.

256 In order to obtain cDNA, reverse transcription (RT) of RNA from extracted RNA was carried

257 out with a PrimeScript TM RT Reagent Kit with gDNA Eraser (TaKaRa, Japan) and oligo-p (dT)

25815 primer, following manufacturer instructions. RT of RNAs was done in equiproportions (i.e.,

259 from equal quantity of RNA) within all compared samples from each experiment.

260 To isolate a partial sequence of an inducible $H S P 70$ for $P$. rubricauda, a pair of primers was 261 designed using a complete sequence of HSP70 from Phaethon lepturus (GeneBank accession

262 number XM_010294882), using Primer 3 input (Untergasser et al. 2012) and a BLAST analysis

263 to identify homologue sequences. A cluster analysis was done using inducible $H S P 70$ sequences

264 described for other birds to identify conserved zones for primer design. Designed primers were

265 5'- TGACAAGTGCCGGGAGG-3' (forward) and 5'-GGAGAAACTCTGCAACCCG-3' 
266 (reverse). A 124-bp PCR product from blood cDNA of P. rubricauda was amplified, purified

267 and sequenced in Macrogen Inc. (Korea). The sequence obtained showed a 99\% similarity with

268 P. lepturus HSP70. The same was done in order to design $\beta$-actin primers for P. rubricauda.

269 Designed primers for $\beta$-actin were 5'-ATGGACTCTGGTGATGGTGTT-3' (forward) and 5'-

270 CTGTAGCCTCTCTCTGTCAGG-3' (reverse). The $\beta$ - actin gene was used as endogenous

271 control for the qPCR analysis as the CT variation between samples was lower than $2 \mathrm{CT}$.

272 Template cDNA was used in a quantitative real-time PCR (RT-qPCR) using commercial

273 fluorescent dye Takyon Low ROX SYBR 2x (Nalgene ${ }^{\circledR}$ ) to quantify transcriptional levels of

274 HSP70. Reactions were run in triplicate in a Real-Time PCR System Agilent Technologies

275 (Stratagene MX3000P). Reactions contained $2 \mu \mathrm{L}$ of cDNA, and $18 \mu \mathrm{L}$ of the master mix, which

276 contained $10 \mu \mathrm{M}$ of each primer, Takyon and Milli-Q water in a final volume of $20 \mu \mathrm{L}$. The

277 initial denaturing time was $3 \mathrm{~min}$ at $95^{\circ} \mathrm{C}$, followed by $40 \mathrm{PCR}$ cycles of $95^{\circ} \mathrm{C}$ for $15 \mathrm{~s}$ and $60^{\circ} \mathrm{C}$

278 for $30 \mathrm{~s}$, followed by $95^{\circ} \mathrm{C}$ and $55^{\circ} \mathrm{C}$ and $95^{\circ} \mathrm{C}$ for $15 \mathrm{~s}$. After the PCR cycles, the purity of the

279 PCR product was checked by the analysis of its melting curve; the thermal profile for melting

280 curve analysis consisted of denaturation for $15 \mathrm{~s}$ at $95^{\circ} \mathrm{C}$, lowered to $55^{\circ} \mathrm{C}$ for $15 \mathrm{~s}$ and then

281 increased to $95^{\circ} \mathrm{C}$ for $15 \mathrm{~s}$ with continuous fluorescence readings. During RT-qPCR, the

282 efficiency of $H S P 70$ gene amplification was approximately equal to that of the housekeeping

283 gene $\beta$-actin (as it was determined by slope calculation). Relative quantification of $H S P 70$ was

284 determined by the comparative CT method ( $\Delta \Delta$ CT method; Livak \& Schmittgen 2001).

285

286 Body Condition

287 Body condition was calculated with a Multiple Linear Regression of body mass as dependent

288 variable with bill length, skull length, wing length and tarsus length as predictors following 
289 Plischke et al. (2010). Based on backward elimination procedure, bill and skull length were 290 discarded from the saturated model. An expected body mass was then calculated for each 291 combination of the size factors as follows: Expected Body Mass $=(1.724 *$ wing length $)+$ 292 (7.357* tarsus length) -26.038 . Finally, body condition was calculated for each bird as a ratio 293 between observed body mass and expected body mass.

\section{Molecular sexing}

296 The red-tailed tropicbird is a monomorphic species that may show cryptic or subtle sexual

297 dimorphism to the human eye (see Ismar et al. 2011). A molecular sexing method using the DNA 298 primers 2550F and 2718R (Fridolfsson and Ellegren 1999) was performed to reliable determine 299 the sex of the individuals. This sexing protocol has been used in previous studies in this species 300 (Ismar et al. 2011; Dehnhard \& Hennicke 2013). Total genomic DNA was extracted from blood 301 samples collected in FTA cards (Whatman paper, GE Healthcare Life Sciences) using the 302 DNeasy Blood and Tissue Kit (Qiagen). Reactions of $10 \mu \mathrm{L}$ total volume consisted of $\sim 100 \mathrm{ng}$ 303 of DNA, 1X PCR buffer [160 mM (NH4)2SO4, $670 \mathrm{mM}$ Tris-HCl, 0.1\% stabilizer], $2 \mathrm{mM}$ $304 \mathrm{MgCl} 2,0.6 \mu \mathrm{M}$ of each primer, $0.25 \mathrm{mM}$ of each dNTPs, $1 \mathrm{U}$ of Taq polymerase, and $0.4 \mathrm{mg}$ $305 \mathrm{~mL}-1$ of Bovine Serum Albumin (BSA). PCR cycles were performed on an Agilent SureCycler 3068800 Thermal Cycler, as follows: $94^{\circ} \mathrm{C}$ for $2 \mathrm{~min}$, followed by 35 cycles of $94^{\circ} \mathrm{C}$ for $30 \mathrm{~s}, 50^{\circ} \mathrm{C}$ 307 for $45 \mathrm{~s}, 72^{\circ} \mathrm{C}$ for $45 \mathrm{~s}$, and a final extension at $72^{\circ} \mathrm{C}$ for $10 \mathrm{~min}$. Individuals were identified as 308 female if visualized PCR products in agarose electrophoresis showed both the $450 \mathrm{bp} \mathrm{CHD1W}$ 309 band and the $600 \mathrm{bp} \mathrm{CHD} 1 \mathrm{Z}$ band, and as male if only the $600 \mathrm{bp} \mathrm{CHD} 1 \mathrm{Z}$ band was present. 310 


\section{Statistical analyses}

312 All analyses were performed in R software (R Core Team, 2017), and figures were made using

313 the package ggplot2 (Wickham 2009). We tested for the effect of sex (male or female) of the

314 birds in the response variables. Because no significant effects were detected, this factor was

315 excluded from further analyses. The three adults rearing chicks were excluded from statistical

316 analyses because physiological responses can vary widely in relation to breeding stage in birds

317 (e.g. Hõrak et al. 1998, Wojczulanis-Jakubas et al. 2015, among others). The birds that had

318 neither eggs nor chicks were pooled with adults having eggs, after determination of no effects on

319 the response variables. However, for modeling, an offset binary covariate was included to

320 indicate whether the birds had an egg or not.

321 Two types of analyses were conducted. Firstly, we focused on determining the stress

322 responses of the breeding birds. These analyses were conducted separately for the two islands

323 because the explanatory variables were different between islands: (a) nests type (exposed vs.

324 protected) for Rapa Nui, and (b) louse flies' parasitic load (number of louse flies per bird) for

325 Salas \& Gómez. For both islands, the response variables were (a) the five leukocyte types

326 counted in blood smears, (b) the proportion of $\mathrm{H}$ and L leukocytes, (c) mRNA HSP70 relative

327 transcriptional level, and (d) the body condition. To analyze the relationship between the

328 explanatory variables for each island and the count of leukocyte cells, we used generalized

329 multivariate models (GLMs). The models were constructed using the manyglm function available

330 in the package mvabund (Wang et al., 2012), fitting a negative binomial distribution selected

331 after model validation. Model significance was calculated using a Wald statistic test applying

332 the anova.manyglm function with post-hoc univariate tests used to determine the responses of

333 each leukocyte cell. Because the counts of leukocyte cells were obtained from the same sample 
334 of blood obtained from each bird, the independent assumption for cell counts is not satisfied.

335 Thus, $p$-values were corrected by shrinking the sample correlation matrix towards identity

336 (Wang et al. 2017) and using a Montecarlo method of resampling with 999 bootstrap iterations.

337 The proportion of $\mathrm{H}$ and L leukocytes was modeled using a univariate logistic regression

338 analysis using a GLM, assuming a binomial probability distribution. Multivariate Analysis of

339 Variance (MANOVA) was performed to test for the response of both the mRNA HSP70 relative

340 transcriptional levels and body condition, between islands and within each colony. The best

341 models for every response variable were selected in terms of the maximum likelihood criteria

342 (Crawley 2007). Model validations were done examining the normality of the residuals (Shapiro-

343 Wilk normality test) generated by each model.

344 The second type of analysis consisted in determining the effect of the body condition of the birds

345 at the level of the five leukocyte cells. A multivariate GLM was applied as described above using

346 the manyglm function but using the body condition (expressed as natural logarithm) as the

347 regressor for leukocyte cell counts, and island as a categorical factor. The model significance and 348 validation were examined in the same way as described above.

350 Results

\section{Stress indicators and its relationship with nest type in the Rapa Nui colony}

352 No significant differences were found in the count of any leukocyte type when comparing

353 between protected and exposed nests (Deviance test $=1.779 ; P=0.830$ ). There were not

354 significant differences between the two nest types in the $\mathrm{H} / \mathrm{L}$ ratio (Residual Deviance $=19.889$;

$355 P=0.330$ ), mRNA $H S P 70$ relative transcriptional level (MANOVA, $F=0.088, P=0.771$ ), nor 
356 body condition (MANOVA, $F=3.495 ; P=0.091$ ). Neither, the $\mathrm{H} / \mathrm{L}$ ratio nor mRNA $H S P 70$

357 relative transcriptional levels showed a relationship to body condition $(\mathrm{r}=-0.382, P=0.198$ and $358 \mathrm{r}=-0.522, P=0.099$, respectively).

359 Eosinophils were the most abundant leukocyte in Rapa Nui, with a total mean of $36.69 \%$, 360 followed by heterophils (31.83\%) and lymphocytes (30.85\%) (Table 1). Monocytes and

361 basophils were the less abundant with a mean of $5.88 \%$ and $0.63 \%$ respectively (Table 1 ). When 362 analysing for nest types, eosinophils were also the most abundant for both categories, with a 363 mean of $40.71 \%$ in protected nests and a mean of $41.31 \%$ in exposed nests (Table 2 ).

\section{Stress indicators and its relationship with louse flies' parasite load in the Salas \& Gómez} colony

367 All flies captured in this study were identified as Olfersia sp. (Diptera: Hippoboscidae)

368 (following Bequaert, 1941; Maa, 1966; and Santos et al. 2014). The median of louse flies'

369 parasitic load was 4 (Range $0-26$ ), with a prevalence of $91 \%$ of parasitized birds. Of 22 red-

370 tailed tropicbird adults assessed in Salas \& Gómez, two birds (9\%) had no flies at the moment of 371 assessment, seven (32\%) had between 1 and 5 flies, 10 (45\%) had between 6 and 11 flies, and 372 only three birds (14\%) had more than 22 flies. In most cases, the 5 minutes' limit was sufficient 373 to capture almost all louse flies inhabiting the birds. In two cases the 5 minutes' limit was not 374 sufficient to capture all the louse flies over the birds. These two birds had 22 and 26 flies each, 375 and at least 10 flies were not captured when the time limit was reached. These extra counts were 376 not added in order to maintain a standard methodology.

377 No significant differences were found in the count of any leukocyte type in relation to louse

378 flies' parasitic load (Deviance test $=2.853 ; P=0.588$ ). The louse flies' parasitic load did not had 
379 a significant effect in the $\mathrm{H} / \mathrm{L}$ ratio (Residual deviance $=20.562 ; P=0.521$ ), the mRNA HSP70

380 relative transcriptional level (MANOVA, $F=0.338 ; P=0.569$ ) nor body condition (MANOVA,

$381 F=1.212 ; P=0.286)$. Neither, the $\mathrm{H} / \mathrm{L}$ ratio nor mRNA $H S P 70$ relative transcriptional levels

382 showed a relationship to body condition $(\mathrm{r}=-0.2217, P=0.2978$; and $\mathrm{r}=0.2946, P=0.1832$,

383 respectively).

384 Eosinophils were the most abundant leukocytes in birds from Salas \& Gómez, with a total 385 mean of $36.77 \%$, followed by heterophils (33.73\%) and lymphocytes (27.73\%) (Table 1).

386 Monocytes and basophils were the least abundant with a mean of $4.36 \%$ and $1.77 \%$ each (Table 387 1).

388

389 Comparison between islands

390 Comparison of the $\mathrm{H} / \mathrm{L}$ ratio between islands showed no significant differences (Residual

391 deviance $=53.347 ; P=0.0644)$. Similarly, the mRNA HSP70 relative transcriptional levels and

392 body condition showed no significant differences when comparing between islands (MANOVA,

$393 F=0.080, P=0.778$ and $F=0.0034, P=0.954$, respectively; Figure 1).

394 The regression analysis using mvabund revealed a significant effect between islands in the 395 count of leukocytes regressed to body condition (Wald test $=4.810, P=0.001$, Table 3 ). Post-

396 hoc univariate test showed an opposite trend between islands in eosinophil, lymphocyte, and 397 monocyte counts related to body condition $(P=0.014 ; P=0.027$, and $P=0.027$, respectively,

398 Table 3). These three leukocytes showed a positive trend when related to body condition for

399 Rapa Nui birds, while a negative trend was detected for Salas \& Gómez (Figure 2). In the case of

400 heterophils and basophils no significant effects were detected $(P=0.479$, and $P=0.207$,

401 respectively, Table 3, Figure 2). 


\section{Discussion}

404 There are several physiological studies in birds focused on passerine nestling immunological

405 response against a wide variety of stressors, including nutritional constraints and parasite

406 infestation (Saino et al. 1998; Lobato et al. 2005; Masello et al. 2009; Martinez-de la Puente et

407 al. 2011). However, there is a lack of studies to understand the adult's physiological responses of 408 some well-documented threats to seabirds (e.g., predation by introduced predators and other 409 anthropogenic perturbations). This is the first physiological study performed to evaluate the 410 effects of both the risk imposed by introduced predators and parasites on selected physiological 411 traits in adults of the red-tailed tropicbird Phaethon rubricauda from the eastern Pacific Ocean.

412 It was expected that the level of threats imposed by introduced predators in the Rapa Nui 413 colony (Flores et al. 2017; Luna et al. 2018), and the level of infestation by louse flies in Salas \&

414 Gómez would be reflected in responses in the H/L ratio (Saino et al. 1998; Caetano et al. 2014),

415 in the mRNA HSP70 level (Morales et al. 2004; Thomson et al. 2010) and body condition

416 (Scheuerlein et al. 2001) in red-tailed tropicbirds. However, no differences were found in any of

417 the stress level indicators assessed when comparing between protected and exposed nests in 418 Rapa Nui, or among birds with different louse flies' parasitic loads in Salas \& Gómez. Similarly, 419 we found a lack of significant difference in the H/L ratio, the mRNA HSP70 level and body 420 condition when comparing between islands. Nevertheless, a significant differentiation between

421 islands was detected in the eosinophil, lymphocyte, and monocyte counts when related to body

422 condition. Because these measures were done under natural scenarios, it was not possible to 423 evaluate colonies free of introduced predators or parasites.

424 Heterophils and lymphocytes are the most abundant leukocyte types among bird's 
425 haematological profiles, composing about $80 \%$ of total leucocyte counts (Davis et al. 2008;

426 Clark et al. 2009). It is noteworthy that eosinophils were importantly elevated in this study, being 427 as abundant as heterophils and lymphocytes, reaching abundances of $35 \%$ on average, in contrast 428 to the average $<2 \%$ previously reported for red-tailed tropicbirds (Dehnhard et al. 2011;

429 Dehnhard \& Hennicke 2013). This unusual abundance was observed in both colonies assessed in 430 the present study, suggesting that eosinophils are elevated in red-tailed tropicbirds inhabiting this 431 ecoregion. While decreased numbers of eosinophils are related to high stress conditions, high 432 numbers have been related to an immune reaction against intestinal parasite loads (Hawkey et al. 433 1983; Maxwell 1993; Davis et al. 2008; Dehnhard \& Hennicke 2013). It is thus possible that 434 unnoticed intestinal parasites are present in both colonies causing this high abundance of 435 eosinophils. However, further studies are necessary to elucidate the exact origin of this 436 observation.

437 It has been reported that blood parameters commonly differ in relation to incubation stage in 438 birds (e.g. Hõrak et al. 1998, Jakubas et al. 2008, Hrabcakova et al. 2014, Wojczulanis-Jakubas 439 et al. 2014, Wojczulanis-Jakubas et al. 2015). However, we were unable determine the laying 440 date of the breeding birds to discriminated between early and late incubation stage to take this 441 into account in our analyses. Fieldwork was conducted in a very limited period within the

442 breeding season and a long-term monitoring of the assessed colonies was not possible due to 443 their isolation and restricted access. On the other hand, we were able to examine the potential 444 effect of bird's sex in our analyses. We found that the sex of the birds does not affected any of 445 the variables assessed. A similar result was reported for a red-tailed tropicbird colony at 446 Christmas Island on the Indian Ocean, where neither leucocyte profiles nor body condition 447 differed significantly between sexes (Dehnhard \& Hennicke 2013). This may suggest that red- 
448 tailed tropicbird males and females equally contributes to the energetic demands of the breeding

449 period (Dehnhard \& Hennicke 2013, Wojczulanis-Jakubas et al. 2015).

450 The lack of differences in any of the physiological stress indicators assessed on adult birds

451 between exposed and protected nests within the Rapa Nui colony may be explained by the

452 absence of differences in the frequency of introduced predators visits between nests types, as

453 found in the experiment with simulated unattended eggs in this colony (Luna et al. 2018). It is

454 worth noting that in the experiment reported in Luna et al. (2018) simulated eggs were placed in

455 empty red-tailed tropicbird nests when no birds were present in the colony. In the present study

456 we further evaluated the potential differences between the two nest categories because the

457 presence and behavior of introduced predators may differ widely between an active v/s an un-

458 active colony. However, both studies seem to suggest that in this colony terrestrial predators visit

459 all nests equally, and aerial predators may not increase predation risk in exposed nests. Even

460 though in the present study each of the active nests were sampled during the timeframe of the

461 fieldwork, further research including a bigger sample size will be necessary to corroborate these

462 results.

463 The lack of correlation between different levels of louse flies' parasitic loads and the assessed

464 stress traits on the Salas \& Gómez colony may be explained by the behaviour of this

465 ectoparasite. During sampling, it was observed that louse flies tended to leave their hosts when

466 these flew away for feeding; and reattached to them when they come back to the colony. This

467 behaviour of the flies may have affected the accuracy in assessing the real parasitic load, and

468 thus affecting results on stress indicators levels. The method used to measure the parasitic load of

469 louse flies in this study should thus be considered as the first evidence of the high prevalence of

470 parasites in this colony, but may not reflect the accumulated parasitic load effect on stress over 
471 time.

472 A possible explanation for the absence of differences in stress indicators between the two 473 assessed colonies in this study might be related to the presence of the native Great Frigatebird 474 (Fregatta minor) in Salas \& Gómez. This species is known to kleptoparasitize on several seabird 475 species, including the red-tailed tropicbird, and also is reported to depredate on small seabird 476 chicks (e.g. Schreiber \& Ashmole 1970; Megyesi \& Griffin 1996). Red-tailed tropicbirds in 477 Salas \& Gómez nests under rocky protection, and no exposed nests were observed in this colony.

478 This rise the question if this nesting behaviour is because of soil's conditions, or if birds prefer 479 protected nests to avoid avian predation by great frigatebirds. Predation of chicks by great 480 frigatebirds has never been reported on any species in Salas \& Gómez, likely due to a lack of 481 observations because of its remote location. Despite this, the presence of this species on a small 482 island like Salas \& Gómez, surrounded by oligotrophic oceanic conditions (Morel et al. 2010), 483 may raise the risk of frigatebirds attempting to depredate on red-tailed tropicbird chicks, with 484 probably similar effects on physiological stress indicators, as introduced predators in Rapa Nui. 485 The only significant difference found in this study was in the eosinophil, lymphocyte, and 486 monocyte counts when related to body condition between islands. Although body condition per 487 se was not a significant factor within islands, the interaction between the two factors (body 488 condition and island) showed a significant effect in the trend of these three leukocytes. For the 489 Rapa Nui colony, the trend was an increase of these three leukocytes with a better body 490 condition. The opposite trend was found for the colony at Salas \& Gómez, where increased

491 levels of these three leukocytes was related to a poorer body condition. Eosinophils,

492 lymphocytes, and monocytes are all involved in the immune response against infections. It may

493 be possible that birds from Salas \& Gómez in a poorer body condition where more susceptible to 
494 an infestation by louse flies, together with unnoticed intestinal parasites. Furthermore,

495 Haemosporidian blood parasites are usually transmitted by louse flies and cause infection

496 (Rahola et al. 2011). These blood parasites were not detected in this study despite of an

497 exhaustive visual examination of blood smears. However, we cannot discard an undetected

498 presence of these parasites in the assessed birds. Genomic techniques may be necessary to detect

499 Haemosporidian parasites from bird's blood samples (see Cassin-Sackett 2020). It is also

500 possible that an infection by parasites is the cause of the poorer condition of some birds at Salas

$501 \&$ Gómez and not that birds in a poorer body condition are more affected by an infection. On the

502 other hand, our results may suggest that birds at Rapa Nui in a better body condition showed a

503 higher immune activity compared to birds in a poorer condition. As stated before, eosinophils

504 were elevated in both colonies, suggesting an infection by unnoticed intestinal parasites in this

505 ecoregion. It may be the case that an additional infection by louse flies -and possible by

506 Haemosporidian blood parasites- at Salas \& Gómez is the cause for the significant difference in

507 the trend of eosinophils, lymphocytes, and monocytes between the islands. However, it should be

508 acknowledged that the colonies were assessed under a natural scenario and several other factors

509 may have influenced the difference of these three leukocytes when related to body condition

510 between the two colonies.

511

512 Conclusions

513 We found a lack of significant differentiation in all the stress level indicators assessed within

514 islands (protected v/s exposed nests in Rapa Nui and different louse flies' parasitic loads in Salas

515 \& Gómez) and between islands. However, this study revealed a significant opposite trend

516 between islands in the eosinophil, lymphocyte, and monocyte counts when related to body 
517 condition. The presence of louse flies in Salas \& Gómez v/s the absence of this parasite at Rapa

518 Nui may be the cause for the significant difference in the trend of these three leukocytes between

519 the islands. Studies of both, intestinal and blood parasites presence in these two colonies, and on

520 the potential effects of other unassessed factors could contribute to better understand the

521 difference found in these three leukocyte counts when related to body condition between

522 colonies and the unusual high eosinophil count for birds in this ecoregion.

523 Even though no significant effect of predator's presence was observed on the physiological

524 condition of adult red-tailed tropicbirds (sub-lethal interaction), attention should be paid on the

525 direct effect of predators (prey mortality) over the Rapa Nui's colony, especially on the

526 vulnerability of unattended chicks and fledglings to predation during the breeding seasons.

527

528 Acknowledgments

529 We are grateful to the Chilean Navy for transport to Salas \& Gómez Island. We also express our

530 gratitude to the indigenous community of Ma'u Henua and to the National Forest Corporation-

531 Rapa Nui (CONAF-Rapa Nui) for allowing access to the colony at Rano Raraku at the Rapa Nui

532 National Park. We would like to acknowledge Pedro Lazo and Graciela Campbell (CONAF-

533 Rapa Nui rangers) for their help during fieldwork. Miriam Lerma and Juan Serratosa (PhD

534 students) collected the samples from Salas \& Gómez in one of the three sampling trips to the

535 island. Finally, we thank to the Agricultural and Livestock Service (SAG), Chile, for providing

536 the necessary permits for bird assessments.

537

538 References

539 
540 Aguirre J, Johow F, Seeger H, Johow JC, Rubio M (2009) Nuevos Registros de aves

541 nidificantes en las islas Desventuradas, Chile Insular. Boletín Chileno de Ornitología 15:44-

54255.

543 Baird RW (1996) Yellow-footed Gull (Larus livens) preys on a Black Storm-Petrel

544 (Oceanodroma melania). Colonial Waterbirds 19:260-261.

545 Bequaert J (1941) The Hippoboscidae of Oceania (Diptera). Occasional Papers XVI: 247-292.

546 Boyd (1951) The external parasites of birds: A review. The Wilson Bulletin 63:363-369.

547 Brown ME (1996) Assessing body condition in birds. Current Ornithology 13:67-135.

548 Brun NT, Bricelj VM, MacRae TH, Ross NW (2008) Heat shock protein responses in

549 thermally stressed bay scallops, Argopecten irradians, and sea scallops, Placopecten

550 magellanicus. Journal of Experimental Marine Biology and Ecology 358:151-162.

551 Caetano JVO, Maia MR, Manica LT, Macedo RH (2014) Immune-related effects from predation

552 risk in Neotropical blue-black grassquits (Volatinia jacarina). Behavioural processes 109:5855363.

554 Cassin-Sacket L (2020) Promising protocols for parasites: Metatranscriptomics improves

555 detection of hyperdiverse but low abundance communities. Molecular Ecology Resources $556 \quad 20: 8-10$.

557 Caut S, Angulo E, Courchamp F (2008) Dietary shift of an invasive predator: rats, seabirds and 558 sea turtles. Journal of Applied Ecology 45:428-437.

559 Clark P, Boardman W, Raidal S (2009) Atlas of Clinical Avian Hematology, Wiley-Blac.

560 Coulson J (2002) Colonial Breeding in Seabirds. In: Schreiber EA, Burger J (eds) Biology of

561 marine birds. Washington, USA, pp 87-113.

562 Crawley M (2007) The R Book. Imperial College London at Silwood Park. UK, 527-528. 
563 Cresswell W (2008) Non-lethal effects of predation in birds. Ibis 150:3-17.

564 Croxall JP, Butchart SHM, Lascelles B, Stattersfield AJ, Sullivan B, Symes A, Taylor P (2012)

565 Seabird conservation status, threats and priority actions: a global assessment. Bird

566 Conservation International 22:1-34.

567 Davis AK (2005) Effect of handling time and repeated sampling on avian white blood cell

568 counts. Journal of Field Ornithology 76:334-338.

569 Davis AK, Maney DL, Maerz JC (2008) The use of leukocyte profiles to measure stress in

570 vertebrates: a review for ecologists. Functional Ecology 22:760-772.

571 Dehnhard N, Hennicke JC (2013) Leucocyte profiles and body condition in breeding brown

572 boobies and red-tailed tropicbirds: Effects of breeding stage and sex. Australian Journal of

573 Zoology 61:178-185.

574 Dehnhard N, Quillfeldt P, Hennicke JC (2011) Leucocyte profiles and H/L ratios in chicks of

575 Red-tailed Tropicbirds reflect the ontogeny of the immune system. Journal of Comparative

$576 \quad$ Physiology B 181:641-648.

577 del Hoyo, J., Elliott, A., \& Sargatal, J. (1992). Handbook of the birds of the world (Vol. 1).

578 Barcelona, Spain: Lynx Editions.

579 Fitze PS, Tschirren B, Richner H (2004) Life history and fitness consequences of ectoparasites.

$580 \quad$ Journal of Animal Ecology 73:216-226.

581 Fleet RR (1974) The red-tailed tropicbird on Kure Atoll. Ornithological Monographs 16: 1-64.

582 Flores M, Schlatter RP, Hucke Gaete R (2014) Seabirds of Easter Island, Salas y Gomez Island

583 and Desventuradas Islands, southeastern Pacific Ocean. Latin American Journal of Aquatic

584 Research 42:752-759.

585 Flores M, Lazo P, Campbell G, Simeone A (2017) Breeding status of the Red-tailed Tropicbird 
(Phaethon rubricauda) and threats to its conservation on Easter Island (Rapa Nui). Pacific

587 Science 71:149-160.

588 Fridolfsson AK, Ellegren H (1999) A simple and universal method for molecular sexing of non589 ratite birds. Journal of Avian Biology 30:116-121.

590 Glue DE (1972) Bird Prey taken by British Owls. Bird Study 19:91-96.

591 Hamer KC, Schreiber EA, Burger J (2002) Breeding Biology, Life Histories, and Life History592 Environment Interactions in Seabirds. In: Schreiber EA, Burger J (eds) Biology of marine 593 birds. Washington, USA, pp 217-261.

594 Hawkey C, Samour JH, Ashton DG, Hart MG, Cindery RN, Finch JM, Jones DM (1983) Normal 595 and Clinical Haematology of Captive Cranes (Gruiformes). Avian Pathology 12:73-84.

596 Hõrak P, Jenni-Eiermann S, Ots I, Tegelmann L (1998) Health and reproduction: the sex-specific 597 clinical profile of great tits (Parus major) in relation to breeding. Canadian Journal of 598 Zoology 76:2235-2244.

599 Hrabcakova P, Voslarova E, Bedanova I, Pistekova V, Chloupek J (2014) Changes in selected 600 haematological and biochemical parameters in debeaked pheasant hens during the laying 601 period. Ankara Üniversitesi Veteriner Fakültesi Dergisi 61:111-117.

602 Ismar SMH, Chong NL, Igic B, Baird K, Ortiz-Catedral L, Fidler AE, Hauber ME (2011). Visual 603 sensitivity, coloration and morphology of red-tailed tropicbirds Phaethon rubricauda 604 breeding on the Kermadec Islands. New Zealand Journal of Zoology 38:29-42.

605 Jacobs SR, Elliott K, Guigueno MF, Gaston, AJ, Redman P, Speakman JR, Weber JM (2012)

606 Determining Seabird Body Condition Using Nonlethal Measures. Physiological and 607 Biochemical Zoology 85:85-95.

608 Jakubas D, Wojczulanis-Jakubas K, Kreft R (2008) Sex differences in body condition and 
609 haematological parameters in little auk Alle alle during the incubation period. Ornis Fennica

$610 \quad 85: 90-97$.

611 Jones HP, Tershy BR, Zavaleta ES, Croll, DA, Keitt BS, Finkelstein ME, Howald GR (2008)

612 Severity of the Effects of Invasive Rats on Seabirds: A Global Review. Conservation Biology

$613 \quad 22: 16-26$.

614 Koop JAH, Kim PS, Knutie SA, Adler F, Clayton DH (2016) An introduced parasitic fly may

615 lead to local extinction of Darwin's finch populations. Journal of Applied Ecology 53:511-

616518

617 Krajick K (2005) Ecology. Winning the war against island invaders. Science (New York, NY)

$618 \quad 310: 1410-1413$.

619 Labocha MK, Hayes JP (2012) Morphometric indices of body condition in birds: A review.

620 Journal of Ornithology 153:1-22.

621 Levin I, Valkiunas G, Santiago-Alarcon D, Lee-Cruz L, Iezhova T, O’Brien S, Hailer F,

622 Dearborn D, Schreiber EA, Robert C, Fleischer R, Ricklefs R, Parker P (2011) Hippoboscid-

623 transmitted Haemoproteus parasites (Haemosporida) infect Galapagos Pelecaniform birds:

624 Evidence from molecular and morphological studies, with a description of Haemoproteus iwa.

625 International Journal for Parasitology 41:1019-1027.

626 Livak KJ, Schmittgen TD (2001) Analysis of Relative Gene Expression Data Using Real- Time

627 Quantitative PCR and the 2 CT Method. Methods 25:402-408.

628 Lobato E, Moreno J, Merino S, Sanz J, Arriero E (2005) Haematological variables are good

629 predictors of recruitment in nestling pied flycatchers (Ficedula hypoleuca). Écoscience

$630 \quad 12: 27-34$.

631 Loye J, Carroll S (1995) Birds, bugs and blood: avian parasitism and conservation. Trends in 
632 Ecology \& Evolution 10:232-235.

633 Luna N, Varela AI, Brokordt K, Luna-Jorquera G (2018) Assessing Potential Predation Risk by 634 Introduced Predators on Unattended Eggs in the Red-Tailed Tropicbird, Phaethon rubricauda 635 , on Rapa Nui (Easter Island). Tropical Conservation Science 11:194008291878507.

636 Maa TC (1966) Diptera: Hippoboscidae; Streblidae. Insects of Micronesia 14:252-274.

637 Martinez-de la Puente J, Merino S, Tomas G, Moreno J, Morales J, Lobato E, Martínez J (2011)

638 Nest ectoparasites increase physiological stress in breeding birds: An experiment.

639 Naturwissenschaften 98:99-106.

640 Masello JF, Choconi RG, Helmer M, Kremberg T, Lubjuhn T, Quillfeldt P (2009) Do leucocytes

641 reflect condition in nestling burrowing parrots Cyanoliseus patagonus in the wild?

642 Comparative Biochemistry and Physiology, Part A 152:176-181.

643 Maxwell M (1993) Avian blood leucocyte responses to stress. World's Poultry Science Journal $644 \quad 49: 34-43$.

645 Maxwell MH, Robertson GW (1998) The avian heterophil leucocyte: a review. World's Poultry $646 \quad$ Science Journal 54:155-178.

647 Megyesi JL, Griffin CR (1996) Brown Noddy Chick Predation by Great Frigatebirds in the 648 Northwestern Hawaiian Islands. The Condor 98:322-327.

649 Ministry of the Environment, Chile. (2017) Fourteen Process of Wild Species' Classification. 650 Retrieved from http://www.mma.-

651 gob.cl/clasificacionespecies/fichas14proceso/FichasFinal_14RCE/

652 Phaethon_rubricauda_14RCE_FINAL.pdf.

653 Møller AP (1993) Ectoparasites Increase the Cost of Reproduction in Their Hosts. Journal of 654 Animal Ecology 62:309-322. 
655 Morales J, Moreno J, Merino S, Tomás G, Martínez J, Garamszegi L (2004) Associations

656 between immune parameters, parasitism, and stress in breeding pied flycatcher (Ficedula

657 hypoleuca) females. Canadian Journal of Zoology 82:1484-1492.

658 Morel A, Claustre H, Gentili B (2010) The most oligotrophic subtropical zones of the global

659 ocean: Similarities and differences in terms of chlorophyll and yellow substance.

$660 \quad$ Biogeosciences 7:3139-3151.

661 Nogales B, Martín A, Tershy B, Donlan C, Veitch D, Puerta N, Wood B, Alonso J (2004) A

662 review of Feral Cat Eradication on Islands. Conservation Biology 18:310-319.

663 Padilla LR, Whiteman NK, Merkel J, Huyvaert K, Parker P (2006) Health Assessment of

664 Seabirds on Isla Genovesa, Galápagos Islands. Ornithological Monograpfs 60:86-97.

665 Plischke A, Quillfeldt P, Lubjuhn T, Merino S, Masello J (2010) Leucocytes in adult burrowing

666 parrots Cyanoliseus patagonus in the wild: Variation between contrasting breeding seasons,

667 gender, and individual condition. Journal of Ornithology 151:347-354.

668 Prys-Jones R, Peet C (1980) Breeding Periodicity, Nesting Success and Nest Site Selection

669 Among Red-Tailed Tropicbirds Phaethon rubricauda and White-Tailed Tropicbirds $P$.

670 lepturus on Aldabra Atoll. Ibis 122:76-81.

671 Quillfeldt P, Ruiz G, Aguilar M, Masello JF (2008) Variability in leucocyte profiles in thin-

672 billed prions Pachyptila belcheri. Comparatibe Biochemistry and Physiology, Part A 150:26-

$673 \quad 31$.

674 Rahola N, Goodman SM, Robert V (2011) The Hippoboscidae (Insecta: Diptera) from

675 Madagascar, with new records from the "Parc National de Midongy Befotaka". Parasite

$676 \quad 18: 127-140$.

677 R Core Team. (2017). R: A language and environment for statistical computing. R Foundation 
678 for Statistical Computing, Vienna, Austria. Retrieved from https:/www.R-project.org/

679 Saino N, Calza S, Møller AP (1998) Effects of a Dipteran Ectoparasite on Immune Response and 680 Growth Trade-Offs in Barn Swallow, Hirudo rustica, nestlings. Oikos 81:217-228.

681 Santos A, López O, Miller M (2014) Hippoboscidae (Insecta: Diptera). Ectoparásitos en aves de 682 Panamá, claves de identificación, hospederos y distribución. Scientia (Panamá) 24:49-68.

683 Scheuerlein A, Van’t Hof TJ, Gwinner E (2001) Predators as stressors? Physiological and 684 reproductive consequences of predation risk in tropical stonechats (Saxicola torquata 685 axillaris). Proceedings of the Royal Society B: Biological Sciences 268:1575-1582. 686 Schreiber RW, Ashmole NP (1970) Sea-Bird Breeding Seasons on Christmas Island, Pacific 687 Ocean. Ibis 112:363-394.

688 Sørensen JG, Kristensen TN, Loeschcke V (2003) The evolutionary and ecological role of heat 689 shock proteins. Ecology Letters 6:1025-1037.

690 Suorsa P, Helle H, Koivunen V, Huhta E, Nikula A, Hakkarainen H (2004) Effects of forest 691 patch size on physiological stress and immunocompetence in an area-sensitive passerine, the 692 Eurasian treecreeper (Certhia familiaris): an experiment. Proceedings of the Royal Society B:

693 Biological Sciences 271:435-440.

694 Thomson RL, Tomás G, Forsman JT, Broggi J, Mönkkönen M (2010) Predator proximity as a 695 stressor in breeding flycatchers: Mass loss, stress protein induction, and elevated 696 provisioning. Ecology 91:1832-1840.

697 Tomás G, Martínez J, Merino S, Martı J (2004) Collection and analysis of blood samples to 698 detect stress proteins in wild birds. Journal of Field Ornithology 75:281-287.

699 Untergasser A, Cutcutache I, Koressaar T, Ye J, Faircloth B, Remm M, Rozen S (2012) Primer3 700 - new capabilities and interfaces. Nucleic Acids Research 40:e115. 
701 Wang Y, Naumann U, Wright ST, Warton DI (2012) Mvabund- an R package for model-based

702 analysis of multivariate abundance data. Methods in Ecology and Evolution 3:471-474.

703 Wickham H (2009) ggplot2: Elegant Graphics for Data Analysis. Springer, New York. URL

704 http://had.co.nz/ggplot2/book. [p144]

705 Wojczulanis-Jakubas K, Jakubas D, Kulaszewicz I, Kidawa D, Taylor JRE (2014) Influence of

706 primary reproductive investments on blood biochemistry, leukocyte profile and body mass in

707 a small Artic seabird. The Auk: Ornithological Advances 131:743-755.

708 Wojczulanis-Jakubas K, Jakubas D, Chastel O, Kulaszewicz I, (2015) A big storm in a small

709 body: seasonal changes in body mass, hormone concentrations and leukocyte profile in the

$710 \quad$ little auk (Alle alle). Polar Biology 38:1203-1212.

711

712

713

714

715

716

717

718

719

720

721

722

723

Figure 2. Relationship among leukocyte cells and ln body condition of adult red-tailed tropicbirds assessed in Rapa Nui and Salas \& Gómez islands. 


\section{Table $\mathbf{1}$ (on next page)}

Leukocyte analysis of the red-tailed tropicbird, Phaethon rubricauda from Rapa Nui and Salas y Gómez islands

Mean estimated values, standard deviation (SD), range of leukocyte counts, heterophil/lymphocyte ratio $(\mathrm{H} / \mathrm{L}$ ratio) and body mass $(\mathrm{g})$ of red-tailed tropicbird adults assessed between August 2016 and June 2017 in Rapa Nui and Salas \& Gómez islands. 
1 Table 1. Mean estimated values, standard deviation (SD), range of leukocyte counts,

2 heterophil/lymphocyte ratio (H/L ratio) and body mass $(\mathrm{g})$ of red-tailed tropicbird adults assessed

3 between August 2016 and June 2017 in Rapa Nui and Salas \& Gómez islands.

4

\begin{tabular}{lcccc}
\hline & \multicolumn{2}{c}{$\begin{array}{c}\text { Rapa Nui } \\
\mathrm{n}=24^{*}\end{array}$} & \multicolumn{2}{c}{$\begin{array}{c}\text { Salas \& Gómez } \\
\mathrm{n}=22^{*}\end{array}$} \\
Leukocytes & Mean $\pm \mathrm{SD}$ & Range & Mean $\pm \mathrm{SD}$ & Range \\
\hline Heterophils \% & $31.83 \pm 14.63$ & $4.00-59.00$ & $33.73 \pm 11.96$ & $12.00-57.50$ \\
Lymphocytes \% & $30.85 \pm 9.95$ & $17.00-53.50$ & $27.73 \pm 8.44$ & $15.50-48.00$ \\
Eosinophils \% & $36.69 \pm 13.74$ & $15.50-66.00$ & $36.77 \pm 11.41$ & $11.00-55.50$ \\
Monocytes \% & $5.88 \pm 2.34$ & $1.50-10.50$ & $4.36 \pm 2.93$ & $0.00-9.50$ \\
Basophils \% & $0.63 \pm 0.90$ & $0.00-3.50$ & $1.77 \pm 2.91$ & $0.00-10.50$ \\
H/L ratio & $1.18 \pm 0.73$ & $0.15-2.77$ & $1.41 \pm 0.77$ & $0.29-3.43$ \\
Heterophils/10,000 erythrocytes & $6.54 \pm 5.04$ & $0.48-17.82$ & $11.79 \pm 7.22$ & $0.28-23.40$ \\
Lymphocytes/10,000 erythrocytes & $6.20 \pm 3.66$ & $0.71-14.14$ & $7.56 \pm 5.22$ & $0.96-25.67$ \\
Eosinophils/10,000 erythrocytes & $7.57 \pm 6.10$ & $1.66-27.06$ & $10.27 \pm 6.45$ & $0.76-23.83$ \\
Monocytes/10,000 erythrocytes & $1.14 \pm 0.78$ & $0.15-3.68$ & $1.41 \pm 1.29$ & $0.00-4.12$ \\
Basophils/10,000 erythrocytes & $0.10 \pm 0.16$ & $0.00-0.65$ & $0.66 \pm 1.27$ & $0.00-4.57$ \\
Total leukocytes/10,000 erythrocytes & $20.40 \pm 11.36$ & $4.33-52.52$ & $29.26 \pm 16.33$ & $2.00-58.23$ \\
Body mass (g) & $827.8 \pm 55.7$ & $740.0-960.0$ & $828.9 \pm 84.2$ & $700.0-990.0$ \\
\hline
\end{tabular}

5

6 *Sample size after exclusion of samples due to deficient conditions of smears and of adults

7 rearing chicks (two from Rapa Nui and three from Salas \& Gómez). See methods for details. 


\section{Table 2 (on next page)}

Leukocyte analysis of the red-tailed tropicbird, Phaethon rubricauda at two nest categories in Rapa Nui

Mean estimated values, standard deviation (SD), range of leukocyte counts, heterophil/lymphocyte ratio ( $\mathrm{H} / \mathrm{L}$ ratio), and body mass $(\mathrm{g})$ of red-tailed tropicbird adults assessed on June 2017 in Rapa Nui at protected and exposed nests. 
1 Table 2. Mean estimated values, standard deviation (SD), range of leukocyte counts,

2 heterophil/lymphocyte ratio (H/L ratio), and body mass ( $\mathrm{g}$ ) of red-tailed tropicbird adults

3 assessed on June 2017 in Rapa Nui at protected and exposed nests.

4

\begin{tabular}{lcccc}
\hline & $\begin{array}{l}\text { Protected } \\
\mathrm{n}=7^{*}\end{array}$ & & $\begin{array}{l}\text { Exposed } \\
\mathrm{n}=8^{*}\end{array}$ \\
& Mean $\pm \mathrm{SD}$ & Range & Mean $\pm \mathrm{SD}$ & Range \\
\hline Leukocytes & $26.29 \pm 15.17$ & $4.00-45.50$ & $31.44 \pm 14.92$ & $9.00-49.50$ \\
Heterophils \% & $32.57 \pm 7.61$ & $24.00-44.00$ & $26.19 \pm 11.31$ & $17.00-53.00$ \\
Lymphocytes \% & $40.71 \pm 14.36$ & $28.00-66.00$ & $41.31 \pm 11.87$ & $27.50-61.00$ \\
Eosinophils \% & $6.86 \pm 2.08$ & $4.50-10.00$ & $6.25 \pm 2.78$ & $1.50-10.50$ \\
Monocytes \% & $0.43 \pm 0.61$ & $0.00-1.50$ & $1.06 \pm 1.32$ & $0.00-3.50$ \\
Basophils \% & $0.90 \pm 0.67$ & $0.15-1.85$ & $1.43 \pm 0.88$ & $0.17-2.77$ \\
H/L ratio & $4.23 \pm 3.02$ & $0.48-8.86$ & $5.58 \pm 4.86$ & $1.72-16.92$ \\
Heterophils/10,000 erythrocytes & $5.04 \pm 3.26$ & $1.95-12.01$ & $4.81 \pm 2.84$ & $0.71-10.14$ \\
Lymphocytes/10,000 erythrocytes & $7.01 \pm 6.39$ & $1.69-20.82$ & $7.69 \pm 4.88$ & $1.66-17.59$ \\
Eosinophils/10,000 erythrocytes & $1.01 \pm 0.50$ & $0.43-1.88$ & $1.04 \pm 0.51$ & $0.15-1.73$ \\
Monocytes/10,000 erythrocytes & $0.04 \pm 0.05$ & $0.00-0.10$ & $0.19 \pm 0.24$ & $0.00-0.65$ \\
Basophils/10,000 erythrocytes & $16.31 \pm 10.52$ & $4.71-37.51$ & $18.27 \pm 9.36$ & $4.33-34.22$ \\
Total leukocytes/10,000 erythrocytes & $831.4 \pm 45.9$ & $770.0-890.0$ & $805.6 \pm 55.9$ & $750.0-920.0$ \\
Body mass (g) & & & &
\end{tabular}

5

6 *Sample size after exclusion of samples due to deficient conditions of smears (one) and of an

7 adult rearing a chick (one). See methods for details. 


\section{Table 3 (on next page)}

Generalized linear models for leukocytes counts

Multivariate and univariate generalized linear models for leukocytes counts of red-tailed tropicbird adults assessed in Rapa Nui and Salas \& Gómez islands. The cell counts were regressed against the birds' body condition for each island (see Figure 2). Significant values are shown in bold. See Materials and Methods for details about modeling. 
1 Table 3. Multivariate and univariate generalized linear models for leukocytes counts of red-

2 tailed tropicbird adults assessed in Rapa Nui and Salas \& Gómez islands. The cell counts were

3 regressed against the birds' body condition for each island (see Figure 2). Significant values are

4 shown in bold. See Materials and Methods for details about modeling.

Multivariate test:

\begin{tabular}{lcccc}
\hline & Res.Df & Df. Diff & Wald test & $P$ \\
\cline { 2 - 5 } (A) Body Condition (log) & 46 & 1 & 2.783 & 0.160 \\
(B) Islands & 45 & 1 & 2.863 & 0.103 \\
A x B & 44 & 1 & 4.810 & $\mathbf{0 . 0 0 1}$
\end{tabular}

Univariate tests:

\begin{tabular}{|c|c|c|c|c|c|c|c|c|c|c|}
\hline & \multicolumn{2}{|c|}{ Eosinophils } & \multicolumn{2}{|c|}{ Lymphocytes } & \multicolumn{2}{|c|}{ Monocytes } & \multicolumn{2}{|c|}{ Heterophils } & \multicolumn{2}{|c|}{ Basophils } \\
\hline & Wald test & $P$ & Wald test & $P$ & Wald test & $P$ & Wald test & $P$ & Wald test & $P$ \\
\hline (A) Body Condition (log) & 1.475 & 0.310 & 0.859 & 0.459 & 1.754 & 0.239 & 2.297 & 0.078 & 1.065 & 0.459 \\
\hline (B) Islands & 1.195 & 0.517 & 0.568 & 0.688 & 0.700 & 0.688 & 1.350 & 0.493 & 2.296 & 0.058 \\
\hline$A \times B$ & 3.190 & 0.014 & 2.704 & 0.027 & 2.814 & $\mathbf{0 . 0 2 7}$ & 0.650 & 0.479 & 1.257 & 0.207 \\
\hline
\end{tabular}

5 
Figure 1

Comparison of physiological stress traits between colonies

Levels of physiological stress traits ( $\mathrm{H} / \mathrm{L}$ ratio, mRNA HSP70 relative transcriptional level, and body condition) of red-tailed tropicbirds assessed in Rapa Nui (RN) and Salas \& Gómez (SG) islands. Bars represent means \pm standard deviation.
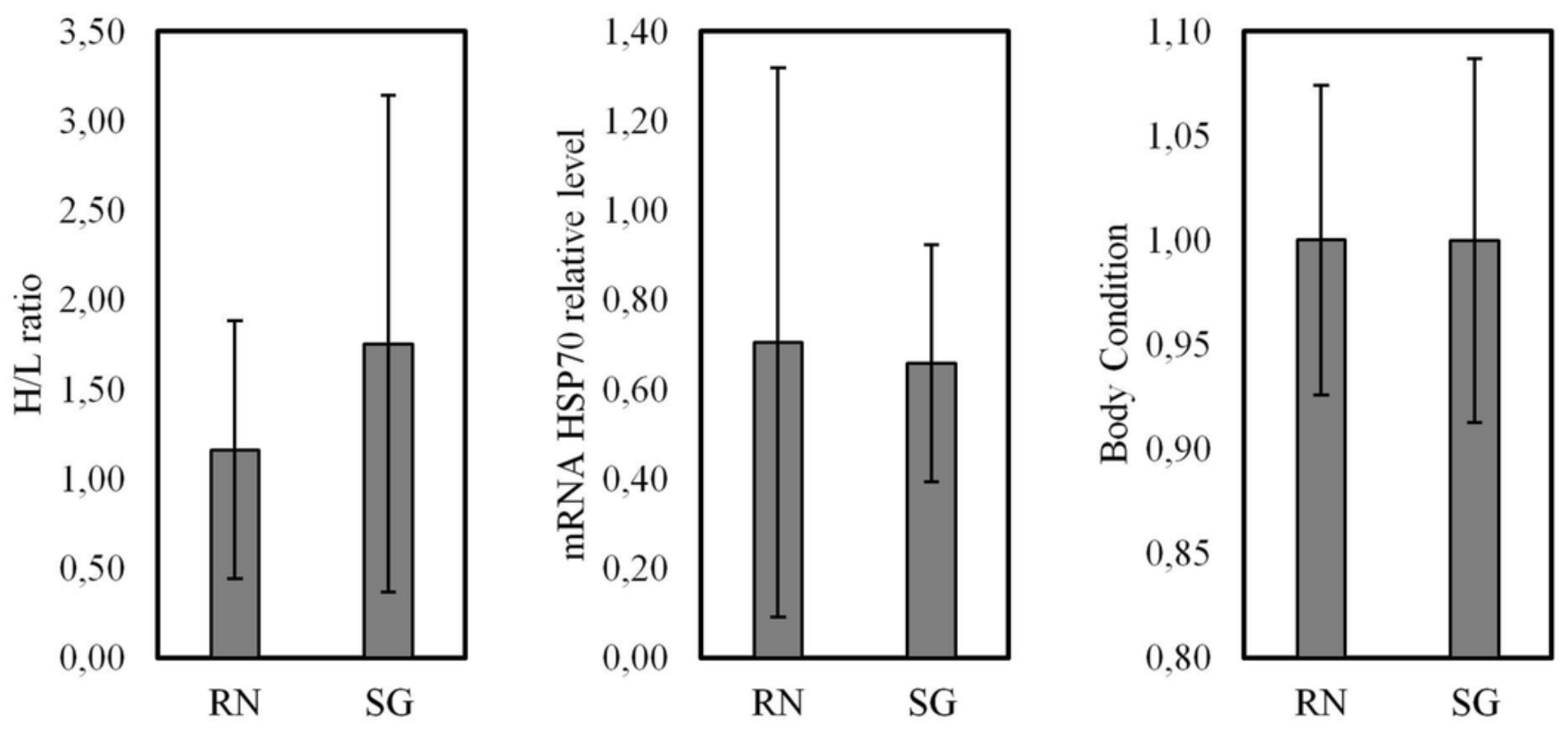
Figure 2

Count of leukocytes regressed to body condition

Relationship among leukocyte cells and In body condition of adult red-tailed tropicbirds assessed in Rapa Nui and Salas \& Gómez islands. 

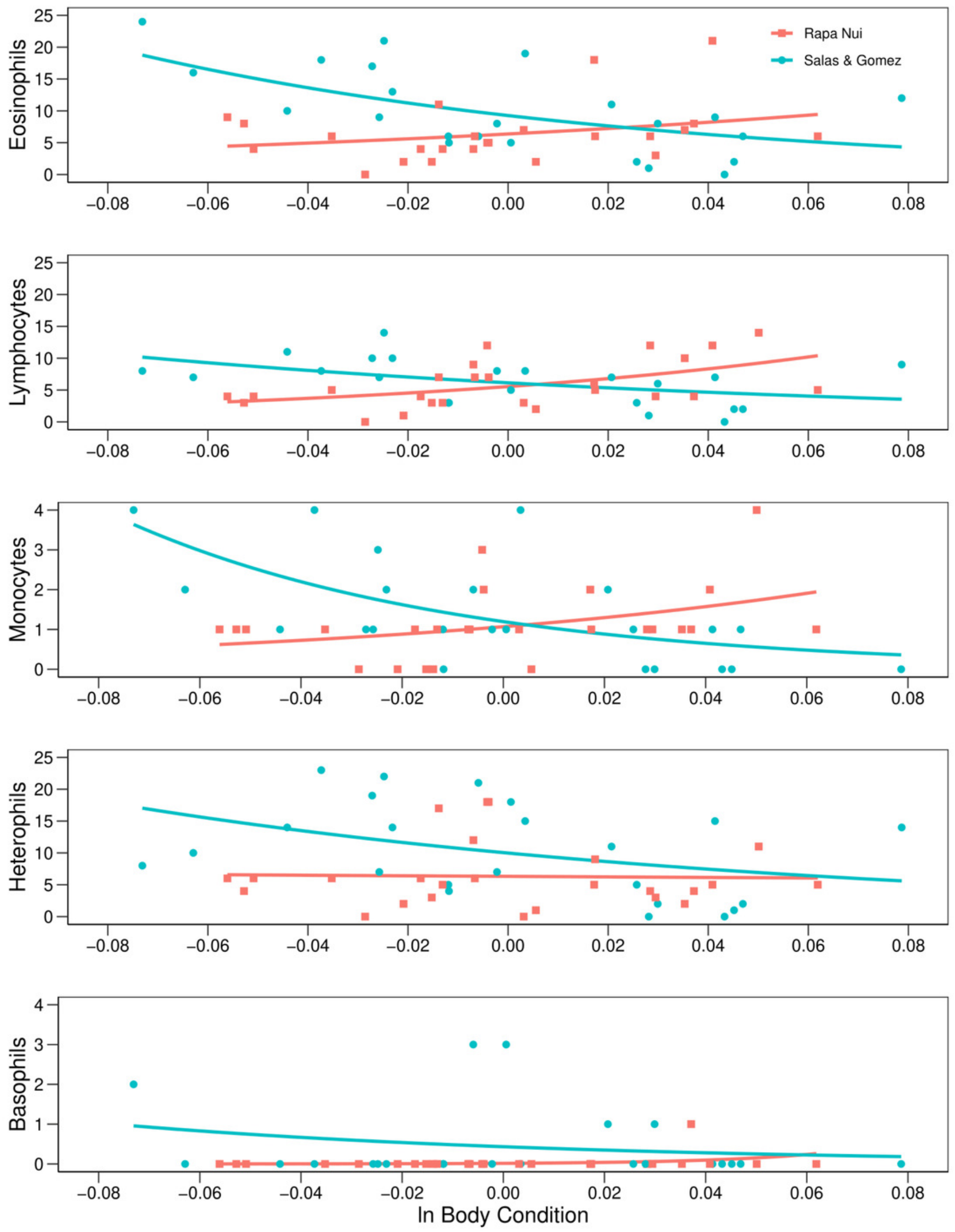